\title{
APPLIED INFORMATION AND COMMUNICATION TECHNOLOGY IN THE ANTI-DOPING AGENCY OF SERBIA - VIEW OF THE SYSTEM ADMINISTRATOR
}

\author{
Miloš Cvjetičanin, \\ Bojan Vajagić, \\ Milica Vukašinović Vesić, \\ Marija Anđelković, \\ Nenad Dikić,
}

Anti-Doping Agency of Serbia,

Belgrade, Serbia

Correspondence:

Nenad Dikić

e-mail:

nenad.dikic@adas.org.rs

\begin{abstract}
:
Anti-Doping Agency of Serbia represents a rare case among governmental institutions considering that statutory job positions include the system administrator. This position is conditioned by the need for performing the following tasks: Design and maintenance of website (mainly for education of athletes, news, etc.), Online education via Moodle platform, Use Facebook for education and communication, Use YouTube and Google books for additional education and communication., Developing android application, Pre-press of all educational material and books. Since one of the main tasks of ADAS is education, applied information and communication technology is very important. Education is recognized as the key reason for reduction of the number of doping positive cases in Serbia during ten years of ADAS existence.
\end{abstract}

Key words:

web site, android application, online education, facebook, information technologies in sport.

\section{INTRODUCTION}

Anti-doping Agency of Serbia (ADAS) was established by the Law on the prevention of doping in sport in 2005, and started with its activities in 2006.

Doping Control Officers of ADAS are trained to perform doping controls at national and international competitions. Overall, during the period from 2005 to 2015, 5,947 doping controls have been performed. Among them are 62 doping positive cases, plus 3 other doping rule violations.

ADAS has four licensed doping control officers in the Union of European Football Associations (UEFA), two licensed doping control officers in the International Federation of Mountaineering and Climbing (UIAA), two supervising doctors in International Basketball Federation (FIBA) and one Doping Control Delegate of European Athletics (EA).

A very important event in the battle against doping in Serbia is the adoption of the Law on Ratification of the International Convention against doping in sport in May 2009 and adoption of new Law against doping in sport in October 2014. By those adoptions, the Republic of Serbia has fulfilled its international obligations in fight against doping in sport and entered the category of countries that legally accept the World Anti-Doping Code. Without legal background, Serbia could be excluded from participating in major international sport events. 
International recognition of work of ADAS is evident in the cooperation with the World Antidoping Agency in the international project "Doctors and doping in sport: experience of 8 countries of the Balkan region", cooperation with FIBA in 4 international projects, as well as cooperation with UNESCO on the project of Anti-Doping education.

Significant and educational work of ADAS, which includes holding regular annual seminars on the fight against doping in sport, lecturing activity, as well as the publishing of books and publications. In 2015, ADAS started organizing the Congress of antidoping prevention in sport.

ADAS operates as an institution, in accordance with the regulations on public services. Anti-Doping Agency of Serbia represents a rare governmental institution considering that statutory job positions include the system administrator. This position is conditioned by the need for performing the following tasks:

- Design and maintenance of website (mainly for education of athletes, news, etc.)

- Online education via Moodle platform

- Use Facebook for education and communication

- Use YouTube and Google books for additional education and communication.

- Developing android application

- Pre-press of all educational material including books.

\section{DESIGN AND MAINTENANCE OF WEB SITE}

ADAS communicates primarily with athletes and sports federations, as well as with sport workers, sport scientists, journalists and public in general. Website [1] is a basic tool for these communications. In addition, a legal obligation of ADAS, as a governmental institution, is publishing information about public procurement, as well as publishing Information Bulletin on the website.

ADAS web site went through four radically different design solutions since it was first set up in 2006. At first, site offered some basic info about ADAS as well as regular news. It was bilingual from start. Static HTML was sufficient web platform for such tasks.

By time, as ADAS engagements widened, site complexity increased as well. We added a downloads section, where various documents and fill-in forms could be downloaded. Every major design iteration brought new contents and recomposition of site sections. News arti- cles, which were regularly illustrated with photographs, very soon became impractical to manage using regular HTML pages, so we included PHP scripts coupled with MySQL database.

After 3 years of existence, the Internet site was composed of well organized sections, for example: "Services" - detailed overview of services we offer, "For athletes" - support for athletes, "Education" - beginning of our online education efforts, "Popular links" - links to sites of various relevant organizations, "News", "Download" - legal documents and many other important documents, etc. This version of site also introduced regularly uploaded press clipping and later on we addedd video clipping and international news related to anti-doping struggle. Another important addition was "Doping Free" service - a way to check whether a supplement has our "Doping Free" sticker - which indicates that particular batch was tested by WADA-accredited laboratory and found to be free of certain doping substances. This site design incorporated detailed pixel graphics and artistically filtered header images, as well as Adobe Flash animated elements.

The next major redesign came in 2013, when we rebuilt site from scratch using WordPress content management system. Among other things, we added a mailing list in order to keep anyone interested informed on the subject of anti-doping, we introduced two very popular services - request for an opinion on dietary supplement / medical drug.

The site consists of the following units:

- Doping Control (Education on doping control procedure, list of doping control officers, prohibited list, etc.)

- TUE (Education in connection with the exemption for therapeutic use, request for an opinion on a medicinal product, etc.)

- Supplements (Education regarding the use of dietary supplements and the risks they carry, the request for an opinion on the supplement, etc.)

- ADAMS (Information regarding ADAMS system and the Registered Testing Pool)

- Education (This segment of the site contains most of educational texts and video recordings of various lectures we held to athletes, including a link to download android app)

- Information (Various information about ADAS, reports on the work of ADAS, download documents, records doping rule violation, important links, etc.) 
Our site received about 97,000 visits and more than 163,000 pageviews since september 2008, which is when we started gathering statistical data. During this period, traffic has increased exponentially. So, over the last 12 months, the site has received about 3.000 or half of all visits of which about $6 \%$ came from Facebook.

Our recently published news article, has more than 1,800 pageviews [2]. The page "Basic Anti-Doping education", received about 7,000 pageviews [3]. Supplementation advice request page has about 5,000 pageviews.

\section{ONLINE EDUCATION VIA MOODLE PLATFORM}

Moodle is a learning platform designed to provide educators, administrators and learners with a single robust, secure and integrated system to create personalized learning environments. Everybody can download the software onto his own web server or ask assistance from knowledgeable Moodle Partners.

With customizable management features, it is used to create private websites with online courses for educators and trainers to achieve learning goals. Moodle (acronym for modularobject-oriented dynamic learning environment) allows forextending and tailoring learning environments using community-sourced plugins. [4]

Athletes who receive a scholarship from the Ministry of Youth and Sports are obliged to receive annual antidoping education. Such education os conducted mainly at our congresses/seminaries, but as large numbers of athletes are often unable to attend these lectures due to scheduled trainings and competitions, we use online course platform to educate these athletes. Our online courses are powered by open-source learning platform Moodle [5]. More than 3,000 athletes went through our Moodle courses so far.

\section{Using Facebook for education and communication}

Due to enormous popularity of social networks, we have decided to engage in this form of communication with athletes and other interested parties in order to spread our education more effectively.

By far the most popular social networking service has been Facebook, so we are therefore using that particular social networking service for communication - mostly with athletes and athletic federations. We also use our presence on Facebook to educate athletes about dietary supplementation, risks related to doping substances, and other relevant issues. Our Facebook page [6] has about 700 likes. Related Facebook page of Sports Medicine Association of Serbia [7] has about 500. Previously mentioned news article about Meldonium had reached more than 3,000 people on Facebook.

\section{Using Youtube for education}

All our educational videos are hosted on YouTube [8]. Furthermore on, we also use YouTube for our video clipping. Our recently uploaded educational film "Doping control procedure" [9] has reached about 60,000 views. We have a total of 200 YouTube hosted videos.

\section{Using Google Books for education}

Google Books is free online service, which enables publishers to publish their books online. The Publisher is offered to specify a price for each electronic book as well as portion of available (freely visible) contents of each book. Publications hosted at Google Books are readily searchable by Google search engine, which makes Google Books the effective means of offering educational material to general public.

Anti-Doping agency of Serbia and Sports Medicine Association of Serbia have put all of the books they published on the Google Books service, free of charge and the whole text is visible online. Also, most of the lectures we gave on various seminaries are hosted at Google Books. All in all, there are about 90 titles [10]. Among most popular titles are: "Prakticna sportska ishrana" more than 22,000 visits, "Prirucnik za klupske lekare" - about 17,000 visits, "Sportskomedicinski pregled" about 12,000 visits...

\section{Android application development}

In the spirit of continuous education of athletes, it was natural for us to expand our educational activities to the next logical platform aimed at athletes - smartphones.

Athletes already regularly use smartphones to access their ADAMS account in order to be able to edit their whereabouts information wherever they are. Athletes are obliged to keep updated information on their physical location on ADAMS system and they often find it difficult to access regular computer at the moment they learn that their whereabouts need to change. Being used to smartphone app usage, athletes can easily start using our application as well. 
We decided to use Android platform, in particular because of its ubiquity. Currently, most widely used Android version is KitKat (Android 4.4) - 34.3\% of market [11]. Older versions, specially versions older than Gingerbread (Android 2.3.3 -2.6\% of market) are not very frequent. However, in order to make our application available to every athlete who is using Android (even versions older than Gingerbread) smartphone, we designed app to work on Froyo (Android 2.2) and all newer versions.

We named the application "ADAS for athletes" and designed it for practical and easy use by athletes on the go [12]. Since the app is still new, the number of users is still insignificant and statistical data is not yet available. Our application offers the following options:

- Prohibited list: our app offers searchable Prohibited list (The list of prohibited doping substances) so that the athlete can quickly check whether some active ingredient present in medication/dietary supplement he/she uses is considered doping.

- Therapeutic use exemption: this option offers the detailed text on the subject of Therapeutic Use Exemption (TUE).

- Supplement/medication advice request form: this will probably be the most popular option as it offers searchable list of issued advices on various drugs and dietary supplements; description of this process: athletes submit the name of supplement, to which we respond by giving our advice about that particular supplement (whether it contains doping substance), and that advice is automatically added to the searchable list of advice available in this application option.

- ADAMS: this option represents a sort of active shortcut; the application checks whether device has ADAMS application installed (ADAMS is a comprehensive database maintained by World Anti-Doping agency which athletes use to fill in data about their whereabouts so they can continually be available for antidoping control), and in case it does, application is launched; in case ADAMS app is not present on the system, the option to install is presented to the user, and if the user doesn't want to install ADAMS app, the simple web browser opens and presents user with $\mathrm{AD}$ AMS web site.

- NEWS: application shows new posts from our web site in the simple manner.

We plan to continue application development, making it even more practical and usable for athletes, and implementing any new athlete-oriented project, specially educative projects into it.

\section{PRE-PRESS OF EDUCATIONAL MATERIAL}

Besides previously mentioned electronic means of education, we are extensively engaged in compiling books and other printed educational material. Books we have published so far cover a wide range of topics including sports medicine, ethical considerations of sport and doping, nutrition, etc.

Every congress we organized/co-organized was accompanied by book of abstracts and other printed material. All events (workshops, seminaries, lecturing sessions, press conferences, congresses, etc.) require educational material combined with branding, leading to our distinctive visual identity presented on banners, posters, fliers. Our slogan "Be healthy, play fair!" was a light motive for several banners, posters and fliers, and it contributed to our success in communicating important messages not only to athletes but to sport federations and team doctors as well.

We have been publishing annually a pocket sized prospect "A pocket guide on doping" since 2008. It presents the most important points to athletes, a list of doping substances, doping control procedure, list of few most important internet sites, etc. These pocket guides can also be downloaded in PDF format on our website [13].

The main tool used for pre-press is Adobe InDesign, along with Adobe Photoshop.

\section{CONCLUSION}

Since one of the main tasks of ADAS is education, applied information and communication technology is very important. Education is recognized as the key reason for reduction of the number of doping positive cases in Serbia during ten years of work of ADAS.

\section{REFERENCES}

[1] http://www.adas.org.rs/accessed 17.03.2016.

[2] http://www.adas.org.rs/vesti/2016/03/08/zasto-jelek-mildronat-meldonium-zabranjen-u-sportu/accessed 17.03.2016.

[3] http://www.adas.org.rs/en/vesti/2016/02/26/adaspokrenuo-program-vrsnjacke-edukacije-o-borbiprotiv-dopinga/accessed 17.03.2016.

[4] https://docs.moodle.org/30/en/About_Moodle 
[5] http://online-kurs.cis.edu.rs/login/index.phpaccessed 17.03.2016.

[6] https://www.facebook.com/ADAS. Srbija/?fref=tsaccessed 17.03.2016.

[7] https://www.facebook.com/MedicinaSportaaccessed 17.03.2016.

[8] http://www.adas.org.rs/youtube-kanal-adas/

[9] https://www.youtube.com/watch?v=zCOsX1CJVps accessed 17.03.2016.
[10] http://smas.org/izdavacka-delatnost.htmlaccessed 17.03.2016.

[11] http://www.bidouille.org/misc/androidcharts accessed 31.03.2016

[12] http://www.adas.org.rs/edukacija/android-aplikacija-adas-za-sportiste/ accessed 17.03.2016.

[13] http://www.adas.org.rs/edukacija/publikacije/ accessed 31.03.2016 